\title{
Psychological capital, subjective well-being, burnout and job satisfaction amongst educators in the Umlazi region in South Africa
}

\begin{abstract}
Authors:
Andrea Hansen ${ }^{1}$

Johanna H. Buitendach

Herbert Kanengoni

\section{Affiliations:}

${ }^{1}$ Department of Psychology, University of Kwa-Zulu Natal, Howard College Campus, South Africa
\end{abstract}

${ }^{2}$ Department of Industrial Psychology, University of the Free State, QwaQwa Campus, South Africa

\section{Correspondence to:}

Herbert Kanengoni

Email:

hkanengoni@gmail.com

\section{Postal address:}

Private Bag $\times 13$,

Phuthaditjhaba 9866,

South Africa

\section{Dates:}

Received: 13 Jan. 2014

Accepted: 05 Sept. 2014

Published: 16 Sept. 2015

How to cite this article: Hansen, A., Buitendach, J.H., \& Kanengoni, H. (2015). Psychological capital, subjective well-being, burnout and job satisfaction amongst educators in the Umlazi region in South Africa. SA Journal of Human Resource Management/SA Tydskrif vir Menslikehulpbronbestuur, 13(1), Art. \#621, 9 pages. http://dx.doi.org/10.4102/ sajhrm.v13i1.621

\section{Copyright:}

(C) 2015. The Authors. Licensee: AOSIS

OpenJournals. This work is licensed under the Creative Commons Attribution License.

\section{Read online:}

Orientation: Challenges faced by educators in South Africa are increasing due to their working conditions, which in turn affects the educators' enthusiasm towards their jobs. Change will likely be witnessed when educators are able to attain a positive and rewarding life, develop and flourish as individuals.

Research purpose: This study sought to investigate the relationship between psychological capital (PsyCap), subjective well-being, burnout and job satisfaction and to explore whether PsyCap mediates the relationship between subjective well-being and burnout.

Motivation for the study: The study is premised on the fact that enhancing the positive attributes and strengths of educators can have a positive impact not only on their performance and commitment, but also on the satisfaction of students.

Research approach, design and method: This cross-sectional study used a biographical questionnaire, PsyCap questionnaire, satisfaction with life scale, burnout inventory and Minnesota job satisfaction questionnaire to collect data from 103 educators.

Main findings: Findings indicated statistically significant relationships between PsyCap, subjective well-being, burnout and job satisfaction. PsyCap was found to mediate the relationship between subjective well-being and burnout.

Managerial implications: PsyCap mediates the relationship between subjective well-being and burnout. Organisations can minimise burnout through the enhancement of positive capacities inherent in PsyCap and the aiding potential of subjective well-being.

Contribution/value-add: The findings highlighted the aiding potential of subjective wellbeing as well as the possible resources PsyCap, subjective well-being and job satisfaction can provide in times of distress.

\section{Introduction}

Teachers often occupy a role far beyond that of an educator to their students, as they aim to understand the plethora of factors affecting the learning abilities of their students and thereby promote a positive and enriching environment for optimal learning of their students (Govender, 2011). Hammett and Staeheli (2009) are of the view that many teachers lack the skills to promote an expected effective and relevant learning environment for their students. Hammett and Staeheli further posit that the challenges and demands teachers face in South Africa are unique, overwhelming and increasing constantly due to the vast socioeconomic disparities teachers find themselves facing. Access to adequate resources has been cited as problematic by many educators in South Africa, which in turn affects the motivation and enthusiasm teachers possess for their jobs and eventually the quality of education students receive (Hammett \& Staeheli, 2009). In recent years, the South African basic education sector witnessed the introduction of different systems of curriculum (such as Outcome-Based Education), which is believed to have placed a significant amount of stress on teachers as they have had to adapt to the changing curricula (Ladbrook, 2009).

Despite the demands placed on teachers, there is a consensus that teachers often concern themselves with trying to fix the problems encountered by their learners, whilst neglecting the need to focus on developing their own strengths and qualities (Hammett \& Staeheli, 2009). Enhancing the positive attributes and strengths of educators leads not only to a positive impact on their performance, commitment and satisfaction, but also to an increase in satisfaction amongst students, which enables them to achieve higher academic results (Luthans, Norman, Avolio \& Avey, 2008). One of the fundamental purposes of teachers is not only enriching the educational needs of the youth, but also inspiring and encouraging students to flourish and live a positive 
and rewarding life. It is imperative that educators in South Africa achieve job satisfaction to enhance commitment to their jobs and performance improvement (Luthans et al., 2008). In order for educators to transfer positive outlook to students and cultivate a generation of positive, flourishing, committed and satisfied youth, who are able to excel in all spheres of life, it is imperative for teachers to become aware of their strengths and positive attributes.

A shared consensus exists amongst researchers (e.g. Clark, 2000; Rothmann \& Barkhuizen, 2008) that education institutions worldwide are developing an imbalance with their environments arising because schools face an overload of demands and are equipped with an undersupply of response capabilities. This is taxing and often contributes to the depletion of internal resources teachers possess for their valuable work. In this regard, it is necessary for a positive approach to be taken in the study of educators and how certain positive capacities can aid in the development and flourishing of educators. It should be noted that in the current study, the terms learners and students as well as the terms teachers and educators are used interchangeably. In light of the above, the study sought to investigate the potential link between psychological capital, subjective wellbeing, burnout and job satisfaction. Psychological capital (PsyCap) and the tremendous potential value it can provide in the work arena were explored. The effect of PsyCap was assessed to determine whether its positive capacities play a role in increasing job satisfaction amongst teachers, whilst decreasing the levels of burnout. In order to address the objective of the study, the following research questions were asked:

- How have psychological capital, subjective well-being, burnout and job satisfaction been conceptualised in the literature?

- What is the relationship between psychological capital, subjective well-being, burnout and job satisfaction?

- Does psychological capital mediate the relationship between subjective well-being and burnout?

\section{Literature review}

This study is situated in the positive psychology subdiscipline, which entails the study of human happiness: the conditions and processes that contribute to the flourishing or optimal functioning of people, groups and institutions (Gable \& Haidt, 2005). This field was propounded to provide an alternative direction to psychology's main focus on weaknesses that plague individuals and creating ways to fix these weaknesses that would create a psychologically and physically sound individual (Seligman, Steen, Park \& Peterson, 2005). On a lighter note, Seligman and Csikszentmihalyi (2000) advocate focus on the positive aspects individuals possess whilst de-emphasising the focus on weaknesses, which is especially relevant for educators within the South African context. The rationale for incorporating the concept of positive psychology is that teachers have a direct impact on the quality of education students receive. It therefore becomes necessary to examine ways of enhancing and cultivating positive capacities (which may act as buffers when educators experience challenging demands and encounter symptoms of burnout) in teachers (Herbert, 2011).

The theoretical framework underpinning this study is the Conservation of Resources theory (COR) (Hobfall, 1989), which highlights elements necessary to form positive emotions, positive individual traits and positive institutions, which are the three main propositions of positive psychology. COR holds that everyone seeks to conserve the quantity and quality of their resources (which contain instrumental and symbolic value to them) and to limit any circumstance that might endanger the quantity or quality of these resources (Lee, 2010). In addition, COR places emphasis on resources (which may include but are not limited to personal characteristics, conditions or energies), which influence an individual's ability to cope with stressors. It is believed that individuals experience stress, even when that stress is merely perceived, as a consequence of factors that threaten to diminish their resources and they then seek to retain their resources in order to maintain equilibrium. Luthans, Avolio, Avey and Norman (2007) share the same sentiments as COR in that individuals who possess all the positive psychological capacities will prove to be better performers in their jobs as well as be more satisfied workers. This can have a significant impact on teacher turnover rates and can have positive influence on the quality of education in South Africa. In light of the above, research illustrating the effect of positive emotions and positive resources, and how these positive capacities may mediate between burnout and improve the well-being of individuals and lead to satisfaction, is important.

\section{Psychological capital}

Psychological capital emerged from the field of positive organisational scholarship, which is premised on the belief that unlocking hidden potential in individuals and focusing on their excellence benefits not only the individual but also the organisation. PsyCap focuses on the personal strengths and positive qualities of individuals and this focus is believed to lead to improved individual and organisational performance (Luthans, Luthans \& Luthans, 2004). Luthans, Youssef and Avolio (2007) contend that PsyCap entails an individual's positive psychological state of development and is characterised by: (1) having confidence (self-efficacy) to take on and put in the necessary effort to succeed at challenging tasks, (2) making a positive attribution (optimism) about succeeding now and in the future, (3) persevering towards goals and, when necessary, redirecting paths to goals (hope) in order to succeed and (4) when beset by problems and adversity, sustaining and bouncing back and even beyond (resilience) to attain success. It is believed that individuals who score high on self-efficacy feel a sense of reliance, certainty and assurance in their skills and knowledge, which enables them to effectively accomplish tasks and be in control of certain situations (Stajkovic \& Luthans, 1998). Optimistic individuals often internalise positive events and externalise negative events (Seligman, 1998). This definition of PsyCap 
emphasises that these positive psychological capacities have developmental properties that can be enhanced as well as be drawn from when individuals feel the need.

Cetin (2011) found job satisfaction to be positively related to the hope, resilience and optimism whilst Herbert (2011) found high levels of hope, optimism, self-efficacy and optimism to be associated with low levels of burnout and stress. The findings of the research conducted by Herbert reflect the same possibilities and assumptions in this study, of positive attributes negating the effects of demands and stressors. In this regard, if teachers could strive towards their goals and overcome barriers, possess confidence in themselves and their work tasks as well as have hope and an optimistic outlook about their work, they would be more likely to report low rates of burnout and high job satisfaction.

\section{Subjective well-being}

Subjective well-being is a derivative of the positive psychology field and entails the cultivating of positive emotions to ensure the optimal functioning and experience of individuals (Ryan \& Deci, 2001). Well-being has been differentiated into two categories: hedonic well-being and eudaimonic wellbeing (Culbertson, Fullagar \& Mills, 2010). The hedonic aspect of well-being refers to subjective emotions such as happiness and the experience of pleasure and is thereby characterised by the presence of positive moods and the absence of negative moods (Ryan \& Deci, 2001). In contrast, the eudaimonic aspect is more cognition based and focused on the motivation individuals possess to achieve their goals and thereby contributes to positive feelings (Culbertson et al., 2010). It is important to distinguish between subjective well-being and happiness, as happiness implies a high ratio of positive to negative feelings (Uchida, Norasakkunkit \& Kitayama, 2004) and subjective well-being comprises a broad category of phenomena that includes people's emotional responses, domain satisfaction and global judgments of life satisfaction (Diener, Suh, Lucas \& Smith, 1999). In this study, only subjective well-being was assessed, as it incorporates how individuals both feel and think about their lives (selfevaluation) (Ozmete, 2011). Research conducted on teacher burnout (e.g. Jackson \& Rothmann, 2006) has focused on how teachers may be unsuited to their environmental demands, which is usually perceived as the reason for the high rates of burnout amongst teachers. A study conducted by Vazi et al. (2011) reported that indicators of subjective and psychological well-being can be evaluated for inclusion in burnout prevention interventions in teachers. However, little or no research has incorporated the health-promoting effect of subjective well-being on burnout, which is reported as having an aiding potential during times of distress (Vazi et al., 2011), making that a notable additive contribution of this study.

\section{Burnout}

Burnout is a term often used to describe instances when individuals experience mental exhaustion (Schaufeli, 2003) and tend to be pervasive in human service occupations such as education (Rothmann \& Barkhuizen, 2008). There have been many definitions proposed to conceptualise burnout, with some referring to it as a cluster of psychological (affective and cognitive), physical and behavioural symptoms (e.g. Van Tonder \& Williams, 2009). However, the most common definition of burnout was put forth by Maslach and Jackson (1986), who conceptualise burnout as a syndrome of emotional exhaustion, depersonalisation and reduced personal accomplishment that can occur in individuals who do 'people work' of some kind. Burnout, known to develop over time depending on various factors, can be understood as a self-perpetuating process that negatively affects individuals in achievement of their goals whilst depleting their resources (Van Tonder \& Williams, 2009). Maslach, Schaufeli and Leiter (2001) distinguish three dimensions inherent in burnout: exhaustion, cynicism and reduced personal efficacy. Exhaustion was described as feelings of decreased emotional resources, cynicism as a pessimistic attitude towards work and reduced professional efficacy as feelings of incompetency. Within the education profession, burnout can be seen as including three distinct dimensions: emotional exhaustion, depersonalisation and low personal accomplishment. Burnout is common amongst educators in South Africa as they often have to teach massive classes (40-60 students) with inadequate resources and teaching equipment; this was especially highlighted upon the introduction of the OBE system in 2000 (Van Tonder \& Williams, 2009). Studies on burnout (e.g. George, Louw \& Badenhorst, 2008; Rothmann, 2003) have shown that burnout plays a factor in job turnover, absenteeism, low morale and job dissatisfaction. Since burnout has often been linked to the experience of stress and subsequently job dissatisfaction, it has become of paramount importance to focus on the positive aspects of individuals and work, which likely lead to job satisfaction.

\section{Job satisfaction}

Locke (1976) defines job satisfaction as 'a pleasurable or positive emotional state resulting from the appraisal of one's job or job experiences' (p. 1304). Implicit in this definition of job satisfaction is the importance of both affect and cognition. The evaluation of a job, therefore, involves both thinking and feelings, which can be linked to the affective and cognitive aspects of subjective well-being. Job satisfaction has been researched extensively to determine its link to worker productivity and organisational effectiveness (e.g. Menon \& Athanasoula-Reppa, 2011) with Shann (1998) emphasising that teacher job satisfaction should be understood as a multi-faceted construct. Shann further proposes that teacher job satisfaction is directly linked to teacher commitment and retention and therefore contributes to school effectiveness. Research on job satisfaction amongst teachers (e.g. Gendin \& Sergeev, 2002) has received increased attention recently as the teaching profession recorded a declining status and due to high turnover rates reported in developing countries over the past few decades (Buckley, Schneider \& Shang, 2005). There is general consensus that different attitudes of teachers, their physical 
TABLE 1: Demographic characteristics of participants.

\begin{tabular}{|c|c|c|c|}
\hline Characteristic & Demographic & Frequency & $\%$ \\
\hline \multirow[t]{2}{*}{ Gender } & Male & 14 & 13.6 \\
\hline & Female & 89 & 86.4 \\
\hline \multirow[t]{4}{*}{ Race } & African & 6 & 5.8 \\
\hline & Indian & 22 & 21.4 \\
\hline & Mixed race & 1 & 1.0 \\
\hline & White & 74 & 71.8 \\
\hline \multirow[t]{5}{*}{ Age group } & $20-25$ & 8 & 7.8 \\
\hline & $26-30$ & 14 & 13.6 \\
\hline & $31-35$ & 9 & 8.7 \\
\hline & $36-40$ & 13 & 12.6 \\
\hline & 41 and older & 59 & 57.3 \\
\hline \multirow[t]{5}{*}{ Qualifications } & Grade 12 & 7 & 6.8 \\
\hline & Diploma & 39 & 37.9 \\
\hline & Degree & 33 & 32 \\
\hline & Honours & 19 & 18.4 \\
\hline & Master's & 5 & 4.9 \\
\hline \multirow[t]{6}{*}{ Tenure } & $1-2$ years & 13 & 12.6 \\
\hline & $3-4$ years & 13 & 12.6 \\
\hline & $5-6$ years & 17 & 16.5 \\
\hline & $7-8$ years & 10 & 9.7 \\
\hline & 9-10 years & 3 & 2.9 \\
\hline & Over 10 years & 47 & 45.6 \\
\hline
\end{tabular}

$N=103$.

well-being, life expectancy, absenteeism, turnover and their success in the profession are all dependent on the degree of job satisfaction experienced. With this in mind, the limited studies (e.g. Herbert, 2011; Wang, Liu, Wang \& Wang, 2012) on relationships between PsyCap and burnout in educational settings within South African situations highlight the need for more focus on assessing the psychological capacities inherent in PsyCap, their possible positive role in enhancing job satisfaction and how they can help decrease burnout amongst educators.

\section{Method}

\section{Measures}

\section{Research participants}

Using convenience sampling, the study sampled 103 educators across four selected educational institutions in the Umlazi region of KwaZulu-Natal. Close to half (45\%) of the sample of 89 women and 14 men had over 10 years' experience in the field. The majority of the sample was in the 41 and older age group (57.3\%) whilst the lowest number belonged to the 20-25 year age group. Most of the participants were White (74), followed by respondents of Indian (22), African (6) and mixed race (1) descent. The majority of participants held a diploma (37.9\%); a large percentage of the participants held degrees (32.0\%), with only a few holding a master's degree (4.9\%). The demographic characteristics of the participants are illustrated in Table 1.

\section{Measuring instruments}

A composite questionnaire was used that consisted of a biographical data sheet, a psychological capital questionnaire, a satisfaction with life scale, the burnout inventory and the Minnesota job satisfaction questionnaire.
Psychological Capital Questionnaire (PCQ): The 24-item PCQ consists of four subscales that measure self-efficacy, hope, optimism and resilience (Luthans, Avolio, Avey \& Norman, 2007) on a six-point Likert scale ranging from 1 (strongly disagree) to 6 (strongly agree). An item reflecting the self-efficacy subscale is 'I feel confident helping to set targets or goals in my work area'. An item reflecting the hope subscale is 'If I should find myself in a jam at work, I could think of many ways to get out of it'. An item reflecting the optimism subscale is 'I always look on the bright side of things regarding my job'. An item reflecting the resilience subscale is 'I usually take stressful things at work in my stride'. A study conducted by Du Plessis and Barkhuizen (2012) in South Africa found the reliability coefficients of the four subscales to be $0.86,0.86,0.77$ and 0.81 respectively, values that indicate a high internal consistency between the items.

Satisfaction with Life Scale (SWLS): To measure subjective well-being the SWLS, developed by Diener, Emmons, Larsen and Griffin (1985), consists of five items measured on a seven-point Likert scale ranging from 1 (strongly agree) to 7 (strongly disagree). A study conducted by Maluka and Grieve (2003) in South Africa found the Cronbach's alpha coefficient of the SWLS to be 0.77 .

Oldenberg Burnout Inventory (OLBI): The OLBI (Demerouti, 1999) used to measure burnout consists of 16 items on a four-point Likert scale with two subscales which measure exhaustion and disengagement. An item reflecting the exhaustion subscale is 'After my work, I usually feel worn out and weary' and one reflecting the disengagement is 'Over time, one can become disconnected from this type of work'. A similar study conducted by Tilakdharee, Ramidial and Parumasur (2010) in South Africa found the Cronbach's alpha reliabilities for the two subscales to be 0.82 and 0.80 respectively and found the overall Cronbach's alpha for the OLBI to be 0.93 .

Minnesota Job Satisfaction Questionnaire (MSQ): The MSQ (Weiss, Dawis, England \& Lofquist, 1967) measures job satisfaction on a five-point Likert scale and consists of three subscales: intrinsic satisfaction, extrinsic satisfaction and general satisfaction. An item reflecting the intrinsic subscale is 'Being able to keep busy all the time'. An item reflecting the extrinsic subscale is 'The way my boss handles his/her workers'. General satisfaction is a summation of all items. A South African study conducted by Buitendach and Rothmann (2009) found the Cronbach's alpha reliabilities for the three subscales to be $0.82,0.79$ and 0.86 ; therefore, these questionnaires were considered acceptable to be used for this study.

\section{Research design}

This cross-sectional study employed a quantitative research design for its objectivity and cost effectiveness and to allow for collection of data that could not directly be observed. The use of a survey was also deemed most appropriate as the 
TABLE 2: Initial eigenvalues for the total variances explained.

\begin{tabular}{lccc}
\hline Questionnaire & Component & \multicolumn{2}{c}{ Initial eigenvalues } \\
\cline { 2 - 4 } & & Total & \% of variance \\
\hline Oldenberg Burnout Inventory & 1 & 5.423 & 33.892 \\
& 2 & 1.837 & 11.483 \\
Psychological Capital Questionnaire & 1 & 8.339 & 34.748 \\
Minneapolis Life Satisfaction Questionnaire & 1 & 5.963 & 29.817 \\
\hline
\end{tabular}

study targeted a large number of participants at one specific time.

\section{Research procedure}

The study protocol was approved by the University of KwaZulu Research Ethics Committee. Permission to collect data in a two week period was also sought from the principals in the selected schools before all participants gave their informed consents in writing to participate in the study. The questionnaire was administered by the researcher directly to each participant in the selected schools. After completion, questionnaires were submitted in a sealed collection box provided by the researcher. Refusal to complete the questionnaire, even after informed consent had been given, was allowed.

\section{Statistical analysis}

Data were analysed using the SPSS statistical program version 21. Firstly, descriptive statistics were computed to obtain the minimum and maximum scores of each questionnaire and to calculate the standard deviation, mean, kurtosis and skewness of values. Using guidelines provided by Nunnally and Bernstein (1994), acceptable Cronbach's alpha coefficients equal to or greater than 0.70 were considered in determining the reliability of the instruments. Exploratory factor analysis (EFA) was conducted on PsyCap, burnout and job satisfaction to investigate construct validity and to determine the factors that best represented the data. EFA allowed for the factors influencing the participants' responses to be determined and allowed for the identification of underlying factors (Suhr, 2006). Inferential statistics were used to make inferences about the population. The current research study made use of the Pearson's $r$ correlation analysis to determine the relationship between PsyCap, subjective well-being, burnout and job satisfaction. Baron and Kenny's (1986) mediation model was used for linear regression analysis to determine whether psychological capital mediated the relationship between subjective wellbeing and burnout. A Sobel test further assessed whether PsyCap carried the effects of subjective well-being to burnout.

\section{Results}

\section{Exploratory factor analysis}

EFA was conducted on the items of the PCQ, the OLBI and the MSQ to determine the underlying factors in the scales. According to Pillay, Buitendach and Kanengoni (2014), factor analysis entails the use of a specialised statistical technique particularly useful for investigating construct validity.

Factor analysis conducted on the PCQ showed a KeizerMeyer-Olkin value of 0.846 , which exceeds the recommended value of 0.6 and the Bartlett's test of sphericity showed a statistical significance. The outcome showed that 23 of the 24 items (all but Item 20) loaded on one factor, which was labelled PsyCap. An analysis of the eigenvalues and the scree plot revealed that only one factor could be extracted (see Table 2). The single factor included all four subscales of PsyCap; therefore, this one factor included items reflecting all four positive psychological states.

An analysis of the eigenvalues in Table 2 showed that two factors could be extracted from the OLBI. When factor analysis was conducted, 12 of the 16 items loaded on the two factors. The Keizer-Meyer-Olkin value was 0.822 , which exceeds the recommended value of 0.6, and the Bartlett's test of sphericity showed a statistical significance. Factor 1 was labelled Disengagement and included items 1, 3, 5, 6, 7 and 15, which indicated that individuals distanced themselves from work and formed negative attitudes about their jobs and work tasks. Factor 2 was labelled Exhaustion and included items 2, 4, 8, 10, 12 and 14, which indicated that individuals felt that their emotional resources were depleted. An item illustrating Exhaustion is 'After my work, I usually feel worn out and weary'.

Factor analysis of the MSQ, an examination of the scree plot and eigenvalues (see Table 2) showed that one factor could be extracted. The Keizer-Meyer-Olkin value (0.766) exceeded the recommended value of 0.6 and the Bartlett's test of sphericity showed a statistical significance. Items 3 , $5,6,9,11,12,13,14,15,16,17,18,19$ and 20 (14 of the 20) loaded on one factor. This single factor was labelled General satisfaction. The General satisfaction factor included both the intrinsic and extrinsic subscales of job satisfaction. General satisfaction included items related to the feelings individuals possessed regarding the nature and aspects of their work tasks and work environment.

\section{Descriptive statistics}

The results of the Komogorov-Smirnov test conducted on PsyCap, subjective well-being, burnout, and job satisfaction revealed no differences between the distributions of the sample and population as the significance values for all four scales were above 0.05 , thus indicating that the sample distributions were normally distributed. The Cronbach's 
TABLE 3: Descriptive statistics and reliability statistics for the scales.

\begin{tabular}{|c|c|c|c|c|c|c|c|}
\hline Variable & Minimum & Maximum & Mean & Standard deviation & Skewness & Kurtosis & $\alpha$ \\
\hline PsyCap & 66 & 138 & 109.77 & 14.72 & -0.3 & -0.14 & 0.91 \\
\hline SW & 5 & 30 & 13.33 & 5.47 & 0.8 & 0.38 & 0.81 \\
\hline Burnout & 18 & 51 & 35.91 & 6.9 & -0.33 & -0.19 & 0.86 \\
\hline Disengagement & 7 & 22 & 14.07 & 3.09 & -0.09 & 0.07 & 0.73 \\
\hline Exhaustion & 4 & 17 & 11.98 & 2.51 & -0.47 & 0.08 & 0.69 \\
\hline GS & 28 & 67 & 52.57 & 8.43 & -0.79 & 0.45 & 0.88 \\
\hline
\end{tabular}

$N=103$.

PsyCap, Psychological capital; SW, Subjective well-being; GS, General satisfaction, $\alpha$, Alpha.

TABLE 4: Correlations between the scales and factors.

\begin{tabular}{|c|c|c|c|c|c|c|}
\hline Measuring instrument & PsyCap & SW & Burnout & $\mathrm{DE}$ & EX & GS \\
\hline PsyCap & 1 & - & - & - & - & - \\
\hline SW & $-0.30 * * \dagger$ & 1 & - & - & - & - \\
\hline Burnout & $-0.62 * *+\dagger$ & $-0.37 * * \dagger$ & 1 & - & - & - \\
\hline DE & $-0.64 * *+\dagger$ & $-0.38 * * \dagger$ & $0.90 * * \dagger \dagger$ & 1 & - & - \\
\hline EX & $-0.54 * *+\dagger$ & $-0.24 *$ & $0.87 * *+\dagger$ & $0.66 * *+\dagger$ & 1 & - \\
\hline GS & $0.52 * * \dagger \dagger$ & $0.42 * * \dagger$ & $-0.55 * * \dagger \dagger$ & $-0.57^{* * \dagger \dagger}$ & $-0.38 * * \dagger$ & 1 \\
\hline
\end{tabular}

PsyCap, Psychological capital; SW, Subjective well-being; DE, Disengagement; EX, Exhaustion; GS, General satisfaction.

$*, p \leq 0.05 ; * *, p \leq 0.01 ; \dagger, r \geq 0.30$ - Practically significant relationship (Medium effect); $\dagger \dagger, r \geq 0.50$ - Practically significant relationship (Large effect).

TABLE 5: Coefficients showing the relative contribution of subjective wellbeing and PsyCap in predicting burnout.

\begin{tabular}{|c|c|c|c|c|c|c|c|c|c|}
\hline & & $\begin{array}{l}\text { Unstandardised } \\
\text { coefficients }(\beta)\end{array}$ & SE & $\begin{array}{l}\text { Standardised } \\
\text { coefficients }(\beta)\end{array}$ & $T$ & $P$ & $F$ & $R$ & $R^{2}$ \\
\hline \multirow[t]{2}{*}{1} & (Constant) & 29.69 & 1.68 & - & 17.7 & 0 & 16.08 & 0.37 & 0.137 \\
\hline & SW & 0.47 & 0.17 & 0.37 & 4.01 & $0.00 *$ & - & - & - \\
\hline & PsyCap & -0.77 & 0.26 & -0.29 & -2.99 & $0.00 *$ & - & - & - \\
\hline \multirow[t]{2}{*}{3} & (Constant) & 61.14 & 4.66 & - & 13.1 & 0 & 36.93 & 0.65 & 0.425 \\
\hline & sW & 0.27 & 0.1 & 0.21 & 2.66 & 0.09 & - & - & - \\
\hline
\end{tabular}

SW, Subjective Well-being; SE, standard error.

$*, p \leq 0.05$.

alpha coefficients for all measuring instruments were acceptable based on the guidelines provided by Nunnally and Bernstein (1994): psychological capital scale $(\alpha \geq 0.70$, $r=0.91)$, subjective well-being scale $(\alpha \geq 0.70, r=0.81)$, burnout scale $(\alpha \geq 0.70, r=0.86)$, Disengagement $(\alpha \geq 0.70$, $r=0.73)$, Exhaustion $(\alpha \leq 0.70, r=0.69)$ and General satisfaction $(\alpha \geq 0.70, r=0.88)$.

\section{Pearson's correlation analysis}

A Pearson correlation analysis was conducted to determine the relationship between psychological capital, subjective well-being, burnout and job satisfaction. The findings in Table 4 indicate that PsyCap had a statistically and practically significant relationship with subjective well-being $(r=-0.30$, $p \leq 0.01$, medium effect), with burnout $(r=-0.62, p \leq 0.01$, large effect), and with both subscales of burnout, disengagement $(r=-0.64, p \leq 0.01$, large effect) and exhaustion $(r=-0.54, p \leq 0.01$, large effect). The correlation analysis also revealed that PsyCap had a statistically and practically significant relationship with job satisfaction (general satisfaction) ( $r=0.52, p \leq 0.01$, large effect). A statistically and practically significant relationship was found to exist between and subjective well-being and burnout $(r=-0.37, p \leq 0.01$, medium effect). Subjective well-being was also found to have a statistically and practically significant relationship with disengagement ( $r=-0.38, p \leq 0.01$, medium effect), with exhaustion ( $r=-0.24, p \leq 0.05$, medium effect) and with job satisfaction (general satisfaction) $(r=0.42, p \leq 0.01$, medium effect). The correlation analysis showed that burnout had a statistically and practically significant relationship with job satisfaction (general satisfaction) $(r=-0.55, p \leq 0.01$, large effect).

\section{Regression analysis}

A multiple regression analysis was conducted to determine whether PsyCap mediated the relationship between subjective well-being and burnout. According to Baron and Kenny (1986), three steps must be fulfilled in order to test for mediation. To test for mediation beta coefficients of different regression equations must be compared (Baron \& Kenny, 1986). Firstly, the mediator should be predicted by the independent variable. Secondly, the dependent variable should be predicted by the mediator and the independent variable. Lastly, the dependent variable should be regressed on the independent variable, whilst controlling the mediator. If all the steps are conducted and they prove significant and the independent variable does not predict the dependent variable whilst controlling the mediator, this indicates perfect mediation.

As shown in Table 5, in step 1, subjective well-being was entered into the analysis and was found to be a statistically significant predictor of burnout $(\beta=0.37 ; t=4.01 ; p<0.05)$. 
In step 2, PsyCap was found to significantly predict burnout $(\beta=-0.29 ; t=-2.99 ; p<0.05)$. Lastly, when subjective wellbeing was added into the regression equation in step 3, only the regression coefficient of PsyCap $(\beta=-0.56 ; t=-7.07$; $p<0.05$ ) was statistically and practically significant (large effect). However, the regression coefficient of subjective well-being was not statistically significant when PsyCap was controlled for in the equation. Findings in Table 5 further demonstrate that $13.7 \%\left(R^{2}=0.137 ; F=16.08 ; p \leq 0.05\right)$ of the variance in burnout was explained by subjective well-being; when PsyCap was entered into the analysis, $42.5 \%\left(R^{2}=0.425\right.$; $F=8.99 ; p \leq 0.05)$ of the variance in burnout was accounted for. From this observation, it can therefore be deduced that PsyCap mediates the relationship between subjective wellbeing and burnout. To further support this outcome, a Sobel test was conducted $(Z=2.77$ and $p=0.005)$. According to this mediation analysis, PsyCap was confirmed as mediating the relationship between subjective well-being and burnout.

\section{Discussion}

The general aim of the study was to determine the potential link between psychological capital, subjective well-being, burnout and job satisfaction and assess whether PsyCap mediated the relationship between subjective well-being and burnout amongst educators in Umlazi, KwaZuluNatal. Luthans, Avolio, Avey and Norman (2007) found that the four subscales of the PCQ can load separately on four different factors, indicating that all four of the subscales can provide a measure of PsyCap and their own subscale as well. The two factors found on the OBLI, which were labelled disengagement and exhaustion, corresponded to the two factors that were found by Demerouti (1999) for the OLBI. The intrinsic and extrinsic subscales of the MSQ loaded onto one factor. George et al. (2008) found a three-factor model for job satisfaction in their research and identified the intrinsic, extrinsic and general satisfaction subscales of job satisfaction. Weiss et al. (1967) suggest that a three-factor model can be used to measure job satisfaction; however, they propose that the third factor was a summation of the intrinsic and extrinsic subscales. This research study thus labelled the one factor General satisfaction and included in it both the intrinsic and extrinsic subscales of job satisfaction. A possible reason why a one-factor model best fitted the data in this research study may be attributed to the relatively small sample size of this study.

Findings from the Pearson's correlations revealed that as educators' levels of subjective well-being increased, their levels of PsyCap decreased. This is contrary to the findings by Avey, Luthans and Jensen (2009), which revealed a statistically and practically significant positive relationship between PsyCap and subjective well-being. The psychological resources in PsyCap have been found to have developmental properties (Luthans, Youssef \& Avolio, 2007). These developmental properties of PsyCap suggest that these psychological resources will not be drawn on if individuals feel satisfied or if there is no need to draw on them. The findings from the study at hand support the state or trait debate surrounding the construct of PsyCap. The result of the Pearson correlation suggests that educators that are satisfied with their lives, experience frequent positive emotions and infrequent negative emotions and are less likely to draw on the internal positive psychological resources inherent in PsyCap, suggesting that when educators' levels of PsyCap are high then their levels of exhaustion and disengagement are low. This can be explained through the theoretical framework underlying this study, COR, which suggests that individuals work to conserve and protect their resources and thus aim to increase their positive resources to deter and cope with stressors (Lee, 2010). The positive psychological resources inherent in PsyCap can serve as a personal characteristic resource. This suggests that as educators experience negative feelings and states due to exhaustion or disengagement as a result of their work tasks or environment, they draw on the positive psychological resources in PsyCap to counter the effects of exhaustion and disengagement.

A study conducted by Herbert (2011) revealed that high levels of PsyCap were associated with low levels of burnout, which supports the possibility of PsyCap being a personal coping resource. The psychological resources inherent in PsyCap (self-efficacy, hope, optimism and resilience) may prevent against the development and progression of burnout. In a similar study, Larson and Luthans (2006) found a statistically and practically significant relationship between PsyCap and job satisfaction. This finding highlights the positive effects of the psychological resources inherent in PsyCap. As educators' levels of PsyCap increase, the more satisfied they are with factors pertaining to their jobs and the more satisfaction they derive from internal aspects of their jobs.

Vazi et al. (2011) suggest that subjective well-being can have a positive effect on burnout and can have aiding potential during times of distress, thus lessening the negative effects or the onset of burnout. This assertion is supported by the findings in this study: as educators' levels of subjective wellbeing increased, their levels of disengagement and exhaustion decreased, thus indicating that subjective well-being may have deterred the feelings of exhaustion and disengagement educators may have experienced in their work tasks and environment. Thus, low levels of disengagement and exhaustion were reported when levels of job satisfaction were high. Job satisfaction was found to have a statistically and practically significant relationship with subjective wellbeing. In a similar study, Malka and Chatman (2003) found a statistically and practically significant relationship between job satisfaction and subjective well-being. This relationship suggests that educators' were not only satisfied with their lives in general, but were also satisfied with the intrinsic and extrinsic aspects of their jobs and work environment. This indicated that PsyCap mediated the relationship between subjective well-being and burnout. The result of the Sobel test confirmed the mediating effect of PsyCap on the relationship between subjective well-being and burnout. This is supported by Luthans, Youssef and Avolio (2007), 
who contend that PsyCap can serve as a psychological resource that can be drawn on during periods of distress. Further research conducted by Vazi et al. (2011) suggests that subjective well-being can have aiding potential during times of stress, thus lessening the negative effects of stress such as burnout. The results indicate the possibility of the positive psychological capacities inherent in PsyCap, coupled with the aiding potential of subjective well-being being carried over to reduce the negative effect of burnout on the wellbeing of educators.

\section{Limitations of the study}

It should be recognised that this research suffers from several limitations that need to be addressed in future studies. Firstly, this study used a relatively small sample size across different educational institutions that were in the same geographical location. Secondly, the participants were conveniently sampled based on easy accessibility and the employment of a cross-sectional design did not allow the establishment of causal direction of relationships between PsyCap, subjective well-being, burnout and job satisfaction. Lastly, the use of selfreported questionnaires in data collection may have affected the reliability and validity of the study as participants may have answered in a socially desirable manner. In this regard, the findings from this research may not be generalised beyond our study population, but this is an exploratory, investigative work from which tentative developments can be deduced rather than conclusive trends.

\section{Recommendations for future research}

Future research should incorporate a larger sample so that more informative results can help to decrease burnout rates amongst educators, whilst increasing their satisfaction and well-being. Larger multi-site investigations may be conducted to increase the reliability of future research and confirm the current findings before firm conclusions can be made regarding the potential link between PsyCap, subjective well-being, burnout and job satisfaction. Future researchers may come up with more definitive results by using longitudinal research designs to assess whether the demands and challenges experienced differ across educational institutions and geographical locations and can thus affect the burnout and satisfaction rates of educators.

\section{Contributions of the study}

There has currently been no research conducted using PsyCap as a mediating variable between subjective wellbeing and burnout. The research study also indicated that job satisfaction could also be drawn on as a resource to mitigate the negative effects of burnout. Little or no research to date has highlighted the aiding potential of subjective well-being for educators or the possible resource job satisfaction can provide in times of distress. To follow on the current study, further research can be conducted to illustrate the role that PsyCap can play as a resource and the role that subjective well-being and job satisfaction can play as resources in times of stress. The findings provided valuable information with respect to increasing satisfaction and well-being rates through the enhancement of PsyCap whilst minimising the burnout rates amongst educators. This is essential for educators as they play an invaluable role and this study's findings are imperative to counter the high burnout rates and, indirectly, the high teacher turnover rates. This study's additive contribution to the body of research conducted on PsyCap in the South African context is noteworthy as it highlights the positive influence PsyCap can have amongst South African educators.

\section{Conclusions and implications}

The positive psychological states inherent in PsyCap can be invested in and managed and can thus be drawn on during times of need to enhance a person's ability to perform and increase organisational performance. The direct positive link between subjective well-being and job satisfaction can be utilised by individuals and practitioners in assessing whether individuals are living up to their expectations or not; if the individuals score high on subjective well-being, they likely achieve job satisfaction. Similarly, if educators experience high levels of PsyCap, it is more likely that they will experience low levels of exhaustion and disengagement. Another general conclusion drawn from the findings is that as educator's levels of PsyCap increase, the more likely they are to be satisfied with factors pertaining to their jobs and the internal aspects of their jobs. An interesting thing from the findings to note is the inference that the more educators are satisfied with their lives in general the more likely they are to be satisfied with the intrinsic and extrinsic aspects of their jobs and work environment. An inverse relationship between job satisfaction and both exhaustion and disengagement may imply that, if educator's levels of job satisfaction are high the more likely they are to experience low levels of exhaustion and disengagement. PsyCap was found to mediate the relationship between subjective well-being and burnout, which implies that the enhancement of the positive capacities of PsyCap and the aiding potential of subjective well-being can help minimise burnout.

\section{Acknowledgements Competing interests}

The authors declare that they have no financial or personal relationship(s) that may have inappropriately influenced them in writing this article.

\section{Authors' contributions}

A.H. (University of KwaZulu-Natal) was responsible for formulating ideas, conducting fieldwork, statistical analysis and presentation of findings. J.H.B. (University of KwaZuluNatal) supervised and made conceptual contributions and to the study. H.K. (University of the Free State) was also involved in statistical analysis, co-authored the results and wrote the final article as well as addressing the editor's concerns. 


\section{References}

Avey, J.B., Luthans, F., \& Jensen, S. (2009). Psychological capital: A positive resource for combating stress and turnover. Human Resource Management, 48, 677-693. http://dx.doi.org/10.1002/hrm.20294

Baron, R.M., \& Kenny, D.A. (1986). The moderator-mediator variable distinction in social psychological research: Conceptual, strategic, and statistical considerations. Journal of Personality \& Social Psychology, 51, 1173-1182. http://dx.doi. org/10.1037/0022-3514.51.6.1173

Buckley, J., Schneider, M., \& Shang, Y. (2005). Fix it \& they might stay: School facility quality and teacher retention in Washington, D.C. Teachers College Press, 107 quality and teacher retention in Washington, D.C. Teachers Col

Buitendach, J.H., \& Rothmann, S. (2009). The validation of the Minnesota Job Satisfaction Questionnaire in selected organisations in South Africa. South African Journal of Human Resource Management, 7(1), 1-8.

Cetin, F. (2011). The effects of the organizational psychological capital on the attitudes of commitment and satisfaction: A public sample in Turkey. European Journal of Social Sciences, 21(3), 373-380.

Clark, B.R. (2000). Collegial entrepreneurialism in proactive universities. Change, 32(1), 10-18. http://dx.doi.org/10.1080/00091380009602704

Culbertson, S.S., Fullagar, C.J., \& Mills, M.J. (2010). Feeling good and doing great: The relationship between psychological capital and well-being. Journal of Occupationa Health Psychology, 15(4), 421-433. http://dx.doi.org/10.1037/a0020720

Demerouti, E. (1999). Burnout: A consequence of specific working conditions among human service and production tasks. Frankfurt/Main: Lang.

Diener, E., Emmons, R.A., Larsen, R.J., \& Griffin, S. (1985). The Satisfaction satisfaction with Life life Scalescale. Journal of Personality Assessment, 49, 71-74. http:// dx.doi.org/10.1207/s15327752jpa4901_13

Diener, E., Suh, E.M., Lucas, R.E., \& Smith, H.E. (1999). Subjective well-being Three decades of progress. Psychological Bulletin, 125, 276-302. http://dx.doi. org/10.1037/0033-2909.125.2.276

Du Plessis, Y., \& Barkhuizen, N. (2012). Psychological capital, a requisite for organisational performance in South Africa. South African Journal of Economic and Management Sciences, 15(1), 16-30.

Gable, S.L., \& Haidt, J. (2005). What (and why) is positive psychology? Review of General Psychology, 9(2), 103-110. http://dx.doi.org/10.1037/1089-2680.9.2.103

Gendin, A.M., \& Sergeev, M.I. (2002). School reform in the mirror of teachers' opinions. Russian Education and Society, 44, 6-19. http://dx.doi.org/10.2753/ opinions. Russian Educ
RES1060-939344126

George, E., Louw, D., \& Badenhorst, G. (2008). Job satisfaction among urban secondary-school teachers in Namibia. South African Journal of Education, 28, 135-154.

Govender, M. (2011). Balancing the educator's rights to fair labour practices and to strike with the right to education. Unpublished master's thesis. Department of Labour Law, Nelson Mandela Metropolitan University, South Africa. Retrieved n.d., from www.nmmu.ac.za/documents/theses/MAHALINGUM\%20GOVENDER.pdf

Hammett, D., \& Staeheli, L.A. (2009). Citizenship education in South Africa: A report to schools. Retrieved n.d., from www.mendeley. com/.../citizenship-education-insouthAfrica-a report-to schools/

Herbert, M. (2011). An exploration of the relationships between psychological capital (hope, optimism, self-efficacy, resilience), occupational stress, burnout and employee engagement. Unpublished master's thesis. Department of Industrial Psychology, University of Stellenbosch, South Africa. Retrieved n.d., from http:// scholar.sun.ac.za/bitstream/handle/10019.../

Hobfall, S. (1989). Conservation of resources: A new attempt at conceptualizing stress. American Psychological Association, 44(3), 513-524. http://dx.doi.org/10.1037/ 0003-066X.44.3.513

Jackson, L., \& Rothmann, S. (2006). Occupational stress, organisational commitment, and ill health of educators in the North West Province. South African Journal of Education, 26(1), 75-95.

Ladbrook, M.W. (2009). Challenges experienced by educators in the implementation of inclusive education in primary schools in South Africa. Unpublished master's thesis. School of Education, University of South Africa, South Africa. Retrieved n.d., from School of Education, University of South Africa, South Africa. Retrieved n.d., from
http://umkn-dsp01.unisa.ac.za/bitstream/handle/.../dissertationlandbrookm.pdf

Larson, M., \& Luthans, F. (2006). Potential added value of psychological capital in predicting work attitudes. Journal of Leadership and Organisational Studies, 13, 75-92. http://dx.doi.org/10.1177/10717919070130020601

Lee, P. (2010). Conservation of resources theory. Retrieved n.d., from http:// petunialee.blogspot.com/2010/04/conservationofresourcetheory.html

Locke, E.A. (1976). The nature and causes of job satisfaction. In M.D. Dunnette (Ed.), Handbook of industrial and organisational psychology (pp. 1297-1349). Chicago, IL: Rand McNally.

Luthans, F., Avolio, B.J., Avey, J.B., \& Norman, S.M. (2007). Positive psychological capital: Measurement and relationship with performance and satisfaction. Personnel Psychology, 60, 541-572. http://dx.doi.org/10.1111/j.1744-6570.2007.00083.x
Luthans, F., Luthans, K.W., \& Luthans, B.C. (2004). Positive psychological capital: Going beyond human and social capital. Business Horizons, 47(1), 45-50. http://dx.doi. org/10.1016/j.bushor.2003.11.007

Luthans, F., Norman, S.M., Avolio, B.J., \& Avey, J.B. (2008). The mediating role of psychological capital in the supportive organizational climate-employee performance relationship. Journal of Organisational Behavior, 29(2), 219-238. performance relationship. Journal
$\mathrm{http}: / / \mathrm{dx}$.doi.org/10.1002/job.507

Luthans, F., Youssef, C.M., \& Avolio, B.J. (2007). Psychological capital: Developing the human competitive edge. Oxford, England: Oxford University Press.

Malka, A., \& Chatman, J.A. (2003). Intrinsic and extrinsic work orientations as moderators of the effect of annual income on subjective well-being: A longitudinal study. Society for Personality and Social Psychology, 29 (6), 737-746. http:// dx.doi.org/10.1177/0146167203029006006

Maluka, C.S., \& Grieve, K. (2003). Determining the suitability of the satisfaction with life and the Rosenberg self-esteem scales in a cross-sectional setting. New Voices in Psychology, 4, 41-50.

Maslach, C., \& Jackson, S.E. (1986). Maslach Burnout Inventory manual. (2nd edn.). Palo Alto, CA: Consulting Psychologists Press.

Maslach, C., Schaufeli, W.B., \& Leiter, M.P. (2001). Job burnout. Annual Review of Psychology, 52, 397-422. http://dx.doi.org/10.1146/annurev.psych.52.1.397

Menon, M.E., \& Athanasoula-Reppa, A. (2011). Job satisfaction among secondary school teachers: The role of gender and experience. School Leadership and

Management, 31(5), 435-450. http://dx.doi.org/10.1080/13632434.2011.614942
Nunnally, J., \& Bernstein, I. (1994). Psychometric theory. (3rd edn.). New York, NY: McGraw Hill.

Ozmete, E. (2011). Subjective well-being: A research on life satisfaction as cognitive component of subjective well-being. International Journal of Academic Research, 3(4), 55-61.

Pillay, K., Buitendach, J.H., \& Kanengoni, H. (2014). Psychological capital, job demands and organisational commitment of employees in a call centre in Durban, South Africa. South African Journal of Human Resource Management, 12(1), Art. \#599, 14 pages. http://dx.doi.org/10.4102/sajhrm.v12i1.599

Rothmann, S. (2003). Burnout and engagement: A South African perspective. South African Journal of Industrial Psychology, 29(4), 16-25. http://dx.doi.org/10.4102/ sajip.v29i4.121

Rothmann, S., \& Barkhuizen, N. (2008). Burnout of academic staff in South African higher education institutions. South African Journal of Higher Education, 22(2), higher education institutions. South African Journal of

Ryan, R.M., \& Deci, E.L. (2001). On happiness and human potentials: A review of research on hedonic and eudaimonic well-being. Annual Review Psychology, 52, 141-166. http://dx.doi.org/10.1146/annurev.psych.52.1.141

Schaufeli, W.B. (2003). Past performance and future perspectives of burnout research. South African Journal of Industrial Psychology, 29(4), 1-15. http://dx.doi. org/10.4102/sajip.v29i4.127

Seligman, M.E.P. (1998). Learned optimism. New York, NY: Pocket Books.

Seligman, M.E.P., \& Csikszentmihalyi, M. (2000). Positive psychology: An introduction. American Psychologist, 55, 5-14. http://dx.doi.org/10.1037/0003-066X.55.1.5

Seligman, M.E.P., Steen, T.A., Park, N., \& Peterson, C. (2005). Positive psychology progress: Empirical validation of interventions. American Psychologist, 60 progress: Empirical validation of interventions. America

Shann, M.H. (1998). Professional commitment and satisfaction among teachers in urban middle schools. Journal of Educational Research, 92(2), 67-73. http:// dx.doi.org/10.1080/00220679809597578

Stajkovic, A., \& Luthans, F. (1998). Social cognitive theory and self-efficacy: Going beyond traditional motivational and behavioural approaches. Organisationa Dynamics, 26(4), 62-74. http://dx.doi.org/10.1016/S0090-2616(98)90006-7

Suhr, D.D. (2006). Exploratory or confirmatory factor analysis? Cary, NC: SAS Institute. Tilakdharee, N., Ramidial, S., \& Parumasur, S.B. (2010). The relationship between job insecurity and burnout. SAJEM NS, 13(3), 254-271.

Uchida, Y., Norasakkunkit, V., \& Kitayama, S. (2004). Cultural constructions of happiness: Theory and empirical evidence. Journal of Happiness Studies, 5, 223-239. http://dx.doi.org/10.1007/s10902-004-8785-9

Van Tonder, C.L., \& Williams, C. (2009). Exploring the origins of burnout among secondary educators. South African Journal of Industrial Psychology, 35(1), 1-15.

Vazi, M.L.M., Ruiter, R.A.C., Van den Borne, B., Dumont, K., Martin, G.M., \& Reddy, P. (2011). Indicators of subjective and psychological well-being as correlates of teacher burnout in the Eastern Cape public schools, South Africa. Internationa Journal of Education Administration and Policy Studies, 3(10), 160-169.

Wang, Y., Liu, L., Wang, J., \& Wang, L. (2012). Work-family conflict and burnout among Chinese doctors: the mediating role of psychological capital. Journal of Occupational Health, 54(3), 232-240. http://dx.doi.org/10.1539/joh.11-0243-OA

Weiss, D.J., Dawis, R.V., England, G.W., \& Lofquist, L.H. (1967). Manual for the Minnesota Ssatisfaction Qquestionnaire. Minneapolis, MN: Industrial Relations Center. 